Ssciendo Studia Anglica Posnaniensia 55s 1 (2020): 223-246

doi: 10.2478/stap-2020-0010

\title{
A COGNITIVE GRAMMAR PERSPECTIVE ON TEMPORAL CONCEPTUALIZATION IN SLA
}

\author{
FRANKA KERMER $^{1}$
}

\begin{abstract}
This article shows how cognitive grammar and cognitive linguistics theory offer a fruitful paradigm within which the process of second language acquisition can be examined. The aim is to describe and examine the benefit of using notions developed within the CG and CL frameworks to the study of crosslinguistic influence, especially conceptual transfer, in multilinguals. In recent years, the growth of empirical research concerning the contribution of cognitive-inspired theories to the study of second language acquisition and multilingualism has grown extensively. This article illustrates the possible contribution of CL to SLA by focusing on one particular line of inquiry: that of construal. Specifically, it examines how the notions developed within cognitive grammar theory can be useful tools for the analysis and comparison of conceptualization patterns of events, thus giving rise to transfer effects stemming from the way a person construes and conceptualizes events. The starting hypothesis is that conceptual transfer effects in the use of the target grammar, in this case the transfer effects in the TIME domain, may originate from the conceptualization patterns that the multilingual has acquired as a speaker of another L1. Previous transfer research has obtained evidence to suggest that patterns of L1 conceptualizations may be transferred into learners' L2 through patterns that are similar to their L1. The utilization of central tools within cognitive grammar in order to unmask conceptual differences represents an important contribution to the state of the art of crosslinguistic influence research.
\end{abstract}

Keywords: Cognitive grammar; construal; tense and aspect; conceptual transfer; multilingualism.

1 German Language, School of Languages and Translation Studies, FIN-20014; University of Turku. franka.kermer@utu.fi 


\section{Introduction ${ }^{2}$}

Crosslinguistic influence (henceforth, CLI) is a central topic in the field of second-language acquisition (henceforth, SLA) and cognitive science. In this line of inquiry, the relationship between language and thought, the possible cognitive consequences of speaking two or more languages, and the cognitive sources and paths of transfer in multilinguals ${ }^{3}$ have been subjects of considerable interest. One aspect that has been approached in this line of research is how language-specific and language-related patterns acquired in the process of first language acquisition (henceforth, L1) influence the ways of conceptualizing, organizing, and expressing information in a second language (henceforth, L2). This article discusses how cognitive grammar (henceforth, CG), one of the most significant projects within the cognitive linguistics (henceforth, CL) movement, can contribute to the investigation of how learners establish form-meaning connections in SLA and how entrenched cognitive patterns in the speakers' L1 exert influence on the knowledge and use of their L2 by focusing on one particular line of inquiry: that of construal in event conceptualization. Specifically, it illustrates how a CG framework of event construal (Langacker 1987, 1991, 2008) can be fruitful in investigating whether L1-specific patterns in the conceptualization and expression of events carry over to the L2. CG offers a comprehensive understanding of cognitive patterns that are involved in the expression of temporality; for example, expressions such as I am hating her systematically tie the physical experience of intensity to the more abstract experience of non-temporal, subjective concerns on the part of the speaker (De Wit \& Brisard 2014). In this sense, speakers would conceptually represent the experience of intensity through the use of the progressive form. This preferred way of conceptually representing the experience of intensity in English may not be preferred in the multilingual's mother tongue, and mapping the conceptual counterparts like the one presented here may pose challenges.

The article is divided as follows: Section 2 presents the theoretical background to this line of investigation. This includes a general introduction to its central tenets, and a general presentation of $\mathrm{CL}$ and Langacker's CG. Section 3 exemplifies Langacker's explanatory descriptions of the relationship between construal patterns and grammatical tense and aspect categories in English. Next, Section 4 discusses Jarvis' conceptual transfer hypothesis and how CG/CL can

2 A preliminary version of this paper was presented by the author at the Cognitive Linguistics in the Year 2018 conference in Poznan. I wish to thank the two anonymous reviewers for their constructive comments on an earlier version of this paper; their feedback has offered a clearer perspective when revising this paper. Any remaining errors or inconsistencies are mine.

3 The terms multilinguals, bilinguals, and language learners are used interchangeably to refer to a person who speaks two or more languages. 
constitute the basis for theoretically grounded premises on the relationship between language and thought when acquiring another language is addressed. Section 5 attempts to show how the notions of conceptualization and construal in CG can be utilized to investigate competing conceptual preferences that speakers employ when organizing and verbalizing information in another language. Furthermore, research hypotheses and methodologies of an ongoing research project, conducted by the author, to investigate mother tongue influence in the expression of temporality in L2 English are discussed.

\section{Cognitive linguistics and cognitive grammar}

\subsection{Central premises}

The school of cognitive linguistics represents a broad theoretical descriptive and comprises a number of prominent theories, such as Talmy's $(1985,1991,1996)$ typological framework on motion events, conceptual metaphor theory (Lakoff 1987; Johnson 1987), and Langacker's cognitive grammar theory, which has been the most influential cognitive approach to grammar (Langacker 1987, 1991, 2008). A CL theory can be characterized by two guiding principles, the generalisation commitment and the cognitive commitment, that are widely shared by cognitive linguists. The generalisation commitment emerged from the assumption that all aspects of language reflect general cognitive processes; it thus is a commitment to the characterization of general organizing principles across different areas of language, such as syntax and semantics (Lakoff 1990; Evans 2019). The second commitment constitutes the view that these general principles are characterized with what is known about the mind and brain from other disciplines (Langacker 1987; Evans \& Green 2006). Among these cognitive principles are categorization, attention, construal, and memory. These core commitments underlie the approach adopted and empirical methodologies employed by cognitive linguists in three main branches: conceptual structure, semantics, and grammar.

In CL and CG, meaning is equated with conceptualization, i.e., any kind of mental experience, which is viewed as a dynamic process of embodied experience as a result of our interaction with the environment (Langacker 2007; Bergen 2012; Bergen \& Chang 2013). Embodied experience describes the close relationship between human experience and bodily experience: the unique nature of our bodies, our location in space and time, and the very subjective relationship between us and reality comprise the specific view of the world each one of us have. Reality, then, is seen as a product, or function, of the mind and body that experiences reality (Bergen 2012). Conceptualization is inherently subjective and includes "besides the objective properties of the described object, the way in 
which the conceptualizer chooses to present it" (Achard 2004: 174). Language, then, reflects the speaker's conceptual system, or, in Langacker's words, "the semantic value of an expression does not reside in the inherent properties of the entity or situation it describes, but critically involves as well the way we choose to think about this entity or situation and mentally portray it" Langacker (1987: 6-7). The dynamic nature of meaning construction emphasizes the speaker's cognitive ability to form temporary mental images of a particular scene that reflects the speaker's conceptual organisation of the situation at that specific point in time. In this view, meaning is not necessarily a property of linguistic expressions in the sense that linguistic units do not carry meaning; rather, meaning resides and is constructed in the speaker's mind (Evans \& Green 2006: $363)$.

\subsection{Grammar in the cognitive linguistics framework}

The cornerstone of CG is its characterization of language structure in terms of general cognitive process, and the ideas of how language and thought interact proposed in CG are now widely held in CL (Evans 2019). Language is seen as a window into human cognition rather than being an autonomous, encapsulated faculty that differs from other cognitive operations. The use of principles of gestalt psychology and aspects of visual perception has allowed cognitive linguists and grammarians to approach and understand the motivation behind linguistic structures in terms of specific cognitive processes, such as construal, attention, categorization, inferencing, and memory storage (Langacker 1996; Bybee 2010). What follows from this conception of language is that meaning plays the central role in linguistic description. In CG, all elements of language are viewed as a vast network consisting of symbolic units that pair sounds with meaning. Assuming that lexicon and grammar are not distinct modules, both lexical and grammatical structures represent symbols and hence convey meaning. These symbols vary along a continuum from very concrete symbolic units, such as dog, to more abstract ones, such as relative clause (Langacker 2008). Additionally, the image-based view of grammar in CG denies the understanding that languages consist of a set of grammatical universals but allows the idea that grammar itself embodies semantic content.

Giving importance to these assumptions bears consequences for the acquisition of languages. In CG, language is seen as a tool for reaching communication-oriented goals in situational contexts in which the language user plays an active role in shaping and constructing language (Langacker 1987: 494). Consequently, as Ellis and Cadierno (2009) describe it, subtle linguistic choices "structure concepts and window attention to aspects of experience through the options specific languages make available to speakers" (2009: 123). 


\title{
2.3. Construal in cognitive grammar
}

The speaker's active role in shaping language use is also manifested in the choice of organizing information and selecting a certain linguistic structure to describe a particular scene. This means that the semantic value of an expression is not entirely a matter of what is conceptualized, but also of how that conceptual content is mentally represented, i.e., construed (Verhagen 2007: 49). Langacker describes the active role of the conceptualizer/speaker in shaping language structure as follows:

\begin{abstract}
A speaker who accurately observes the spatial distribution of certain stars can describe them in many distinct fashions: as a constellation, as a cluster of stars, as specks of light in the sky, etc. Such expressions are semantically distinct; they reflect the speaker's alternate construals of the scene, each compatible with its objectively given properties. [...] Various dimensions of imagery (i.e. construal) must be recognized, the most significant being the profile/base distinction. (Langacker 1990: 61)
\end{abstract}

Construal, the ability to parse the properties of a situation and select the most fitting structural choice from among the open-ended inventory of linguistic choices (Givón 1989: 90) is, in large measure, influenced by the nature of our physical bodies, perspective, and choice to focus on more salient aspects of a situation while backgrounding others. The conventions for construing the world around us are deeply entrenched in the speech community in which the individual speaker participates (Jarvis 2011: 4); as a result, construal occurs both at the individual and at the language level, with different languages offering distinctive conventions for construal.

One of the construal processes recognized highly relevant in expressing thought linguistically is the profile/base distinction, a subtype of figure/ground perception grouping in gestalt psychology (Langacker 1987; Talmy 2000; Croft $\&$ Cruse 2004). The focus of the speaker's attention corresponds to the profile at the conceptual level. A linguistic expression evokes a frame, the base, and within that base primary focus is conferred on the entity that stands out most prominently and is the specific focus of attention, the profile. The profile thus is a substructure of the base that receives the most prominence and is foregrounded against the base (Langacker 2008). Other central components in any construal are ground and scope. The ground designates the context that is necessary for understanding an expression and includes the speech participants and time of speech, and, at a conceptual level, makes up the conceptual core. Ground entities are an inherent part of the conceptual content but can be suppressed in the sentence structure (Radden \& Dirven 2007: 46). The viewing frame that a person adopts when visualising a scene corresponds to the scope of conceptual content which a 
sentence structure evokes (Langacker 1990: 62). A speaker can construe a scene with a maximal or restricted viewing frame. In a maximal viewing arrangement, the speaker construes the full array of the conceptual content, whereas a restricted viewing frame comprises selected segments of that maximal scope that directly presupposes the expression's profile (Casad 1996; Langacker 1999: 49). The maximal scope can be thought of as foregrounding the immediate scope. The field of our vision, however, is limited, and we are only able to perceive a fragment of our spatial surroundings; hence, the scope of an expression reflects what a person can mentally encompass at any moment in time (Langacker 2008: 62f).

\section{Construal of temporal relationships in cognitive grammar}

In this section, I will present an account of the theoretical prerequisites pivotal for the conceptual and semantic analysis of tense and aspect marking in CG. In the construal of temporality (see Table 1), the speaker describes the temporal relationship of an entity to the ground, to the here and now, by establishing a conceptual relationship with the scene. The use of tense and aspect structures allows the speaker to specify the location of the conceived temporal relationship: tense signifies when and with which likelihood something takes place while grammatical aspect signifies whether the event is construed maximally or with a restricted viewing frame (Langacker 1991, 2008; Michaelis 2004; Boogaart \& Janssen 2007).

Table 1. Event construal patterns (based on Langacker 1987, 1996, 2008)

\begin{tabular}{|c|c|}
\hline Category & Construal patterns/operations \\
\hline Function of tense & Temporal or epistemic judgement \\
\hline Viewing frame & Maximal or restricted \\
\hline Temporal reference point & Viewing direction \\
\hline Degree of subjectivity & Objective or subjective \\
\hline Dynamicity & Summary or sequential scanning \\
\hline
\end{tabular}

Tense serves two functions: the temporal function, which indicates the relationship between the ground and the event in the domain of time, and the epistemic function, which represents the speaker's knowledge about the existential status of the event. If a situation is conceived as true and real, a present or past tense marker is required, such as in (1) below. Here, the past -ed marker indicates that the event of raining is accepted as real. In addition to portraying the event as real, the speaker refers to a past instance of the event. In example (2), in contrast, the speaker does not portray the occurrence of the event in time with 
respect to the ground but imposes a non-temporal interpretation of the event. In this case, the use of past tense of the modal may open up a hypothetical space that is still close to reality (Niemeier 2013). The speaker assesses the likelihood of the event's occurrence, and in this case, the modal places the event outside reality and hence indicates that the event is not accepted as real.

(1) It rained yesterday.

[temporal meaning]

(2) It might rain.

[epistemic judgement]

The second category pertains to the distinction between a maximal and restricted viewing frame that a speaker imposes on a given scene. Choosing a maximal or restricted viewing frame corresponds to the absence or presence of aspectual markers at the grammatical level. ${ }^{4}$ While the presence of tense is obligatory in a finite clause, marking for grammatical aspect is optional. The progressive construction does not specify the relationship between the ground and the profiled process, but rather allows the speaker to impose a particular view on the scene, either maximal or restricted. In other words, the progressive has no temporal dimension; rather it serves a modifying function in the sense that it defines the process profiled by the main verb more precisely (Langacker 1991: 197). This is also an example of the profile/base distinction: the progressive in English profiles an inherent component of the process/event, while backgrounding the beginning and end point.

The type of viewing arrangement chosen to construe a scene is often a matter of the speaker's general and contextual knowledge as well as his visual experience. The aspectual properties of various kinds of processes can be explained in terms of bounding (i.e., whether or not a profiled relationship is construed as inherently bounded in its temporal extension) and in terms of heterogeneity (i.e., whether or not the segments of a profiled relationship are construed as involving a change through time). In the absence of an aspectual marker, a verb designates a bounded event that "appears 'onstage' within the temporal scope" (Langacker 2008: 65). In this viewing arrangement, the immediate scope accounts for a time span sufficient for the event, including its

$4 \quad$ In English, one cannot discuss grammatical aspect without lexical aspect. In a CG analysis of lexical aspect, the basic aspectual distinction made by Langacker involves the perfective/imperfective organisation of verbs; the aspectual properties of various kinds of processes, profiled by the verb, can be explained in terms of bounding (i.e., whether or not a profiled relationship is construed as inherently bounded in its temporal extension) and in terms of heterogeneity (i.e., whether or not the segments of a profiled relationship are construed as involving a change through time). In this discussion, I will not outline how inherent aspectual properties of processes interact with tense/aspect marking, but rather show how a speaker's shift in perspective interacts with progressive marking at the grammatical level. 
initial and end state. A present-progressive construction, on the other hand, imposes a restricted scope on the verb and profiles only a series of components of the bounded process, thereby backgrounding its initial and final boundaries (Radden \& Dirven 2007; Langacker 2008; Brisard 2013).

(3) Ann cuddled the baby.

[maximal viewing frame]

(4) Ann was cuddling the baby.

[restricted viewing frame]

In example (3), the choice of the non-progressive aspect gives rise to the speaker's maximal viewing frame with which the scene is construed. The event is bounded, with clearly defined initial and final boundaries, and comprises a series of non-identical sub-events. As a result, the situation <CUDDLE THE $\mathrm{BABY}>$ in (3) is viewed in its entirety. If the speaker imposes a restricted viewing frame, such as in (4), a close-up view on the unfolding of the event is offered. Here, the progressive in (4) zooms in on the event $\langle$ CUDDLE THE BABY $\rangle$ and relegates the initial and final component to the background of attention, while attending to only a fragment of the entire process that is now construed as being homogeneous. Whereas the situation in (3) is seen as complete, the situation in (4) is construed as being ongoing and is susceptible to change. One could also suggest that in order to impose an imperfective interpretation of the event the speaker must adopt a proximal perspective, while a perfective interpretation requires a maximal perspective on the event (Droźdź 2018).

Inherent aspectual properties of a situation interact with grammatical aspect in the sense that the type of the situation, whether it indicates a change of state through time or endures through time with little or no change within and beyond the immediate scope, and the speaker's perspective, which is either proximal or distant, render various form of viewing arrangements at the conceptual level.

(5) He hates her.

[maximal viewing frame]

(6) He is hating her.

[restricted viewing frame]

In (5), we observe that internally unbounded situations, involving a lexically stative verb, endure through time without any specified starting or end point. Prototypically, these type of situations are construed as homogeneous, i.e., nothing changes or happens within or beyond the immediate scope. These types of situations are also construed with a maximal viewing frame. The speaker's shift in perspective and subjective construal of the situation can change the prototypical semantic categorization and the non-dynamic nature of the scene, as exemplified in (6). Here, the progressive presupposes a perspectival shift from a state predication to a dynamic predication and imposes implicit boundaries within the maximal scope. Our contextual knowledge and the restricted viewing frame 
enable us to conceive the situation in (6) as dynamic and temporary. The endpoint of the event is left implicit and has background prominence.

Next, the speaker's viewing direction and its effect on encoding temporal functions is discussed. The ground, the space for apprehending the conceptual content, serves the function of anchoring the occurrence of an event in time relative to time of speaking ("now"). In certain viewing arrangements, the speaker is able to accommodate an anchor time, a temporal relevance time, to direct the hearer's attention to a relevant time span that is not the time at which the event occurred. Normally, the temporal reference point is part of the ground, but, depending on different construals with which a situation is viewed, the speaker can shift his viewpoint to the past or future and access the event in question through this additional space (Zagona 2007). The notions of speech time, event time, and reference time are illustrated in the examples given below:

(7) When I got to the station, the train had already left.

(8) Harry has accepted the job.

(9) I'll be home tomorrow night.

In all three examples, the speaker is located in the ground, and the speech time corresponds to now. Event time, the time at which a situation is instantiated varies in the examples: in (7) and (8) the speaker opens up a past space for the events while in (9) the focus of the speaker is on a time span lying ahead in the future. The speaker's own viewpoint, the temporal reference point, allows to direct the focus of attention to an additional time span, either prior or posterior to event time. In the second part of the sentence in (7), the train had already left, the speaker opens up a space anterior to the past event, thus reporting the situation of the train leaving from the viewpoint of the past event (getting to the station) and not from the present moment. In (8), the speaker's viewpoint coincides with the present time, as indicated by the present tense marking of the verb have. The focus lies on the present time of the past event, which is often referred to as current relevance, or, as Brisard (2013: 232) states, on the 'presentness' of the resultant state (Harry accepting the job). Lastly, the event time for a proposition such as in (9) lies in future time, tomorrow night. The speaker reports the future event from the present time, the ground space, as indicated by the time adverb tomorrow, and the focus is future time at which the event takes place.

The notion of subjectivity pertains to the distinction between subjective and objective construal and the role of the speaker in the overall viewing arrangement. More precisely, subjectivity describes a shift in the speaker's vantage point from a relatively objective construal of an entity to a more subjective one (Langacker 2000: 297). The sentence displayed below illustrates an example of more subjective variations of tense and aspect. 
(10) He's liking her more and more. [subjective construal]

The instance of the present progressive in example (10) is used to indicate intensification. It does so by imposing a much more dynamic construal upon the verb like than does its prototypical semantic categorization as a stative verb. Here, the progressive presupposes a perspectival shift from a state predication (he likes her) to an event predication. The situation of liking her more and more constitutes a subjective, non-temporal construal, whereby the passivized situation is perceived as bounded and dynamic. Furthermore, the example constitutes a shift in construal of vantage point in the sense that the speaker views the situation of liking her subjectively, i.e., the speaker's positive attitude is represented in the sentence. Other usage types in the non-temporal, subjective category of the English progressive include surprise and tentativeness (De Wit $\&$ Brisard 2014).

As mentioned earlier, every linguistic expression stimulates a representational image in which some features are seen more prominent than others. This image has to do with how the speaker structures and organises the environment and situations around him, regardless of what the objective nature of that scene looks like in reality. As to the temporality of a situation, there are two ways of construing a scene: we can either examine it like a photograph or watch it like a motion picture (Langacker 1987: 145). Our mental capacity to track a relationship through time is known as mental scanning. Via sequential scanning, analogous to examining a photograph, a speaker tracks each configuration of a relationship from one moment to the next, as in I walked to the shop and He fell. The speaker's ability to track and assess each individual stage of the entire scene is thus also referred to as as real-time viewing experience. Via summary scanning, on the other hand, the configurations of a relationship are scanned as a single, overall conception, as in I am walking to the shop and He took a fall. The reading here is cumulative in nature and the speaker construes the individual facets of the entire scene as a single complex arrangement that are simultaneously available.

(11) I walked to the shop.

(12) He fell.

(13) I am walking to the shop.

(14) He took a fall. [sequential scanning]

[sequential scanning]

[summary scanning]

[summary scanning] 


\section{Conceptual transfer in SLA}

\subsection{Overview}

The term "conceptual transfer" speaks broadly to the crosslinguistic influence stemming from the way a person attends to, perceives, construes, conceptualizes, interprets, categorizes or recalls experience with the environment (Jarvis \& Pavlenko 2008; Odlin 2008, 2010; Jarvis 2011, 2016), an idea that has been widely discussed in an attempt to investigate cases of L1 influence on L2 use that goes beyond structural and semantic well-formedness and extends to processes and representations at the conceptual level (Jarvis 2011). For instance, multilinguals' choice of referring to spatial relationships largely represents ways of conceptualizing and expressing meaning that are specific to the experiences in their first language, as shown in Jarvis (2016: 627). In an earlier study (Jarvis \& Odlin 2000), transfer effects were visible in Finnish and Swedish learners of English who showed different conceptual preferences for using spatial prepositions when describing a scene of two people sitting in or on the grass in front of a house. While both prepositions are grammatically correct, Finnish speakers generally used the preposition on, whereas the Swedes preferred the preposition in when describing the scene. Jarvis hypothesized that Finns may have considered the Finnish word nurmikko, which refers to grass in someone's yard, instead of the word heinikko, which refers to grass in a field when considering the scene of two people sitting in/on the grass in front of a house. Since the word nurmikko in Finnish requires the use of the external locative case (nurmikolla, "on the grass"), it may have been possible that Finnish speakers relied on their L1-based experience when describing the scene in their L2. This observation shows that patterns of thinking and ways of organising information are affected by the different conventions for the construal of spatial relation in Finnish and Swedish, respectively.

Though the idea of conceptual transfer has been sporadically discussed in earlier works (Kroll \& Potter 1984; MacWhinney 1992), the introduction of the Conceptual Transfer Hypothesis (CTH) by Jarvis (2007) and Jarvis and Pavlenko (2008) has produced a revival of interest in theoretical and methodological issues regarding conceptual transfer. In this article, the scope of conceptual transfer is in line with Jarvis' $(2011,2016)$ perspective on the interplay of thought and language in SLA in at least two regards. First, conceptual transfer is understood as an approach to research in which an attempt is made to trace CLI effects in light of theoretical of empirical advances within the CL enterprise (Jarvis 2011: 3). Second, studies on cognitive consequences of using more two or more languages should be seen to form a continuum with studies firmly grounded in Slobin's thinking-for-speaking hypotheses on one end of the continuum and 
Whorf's linguistic relativity hypothesis on the other (Han \& Cadierno 2010; Ewert 2016; Jarvis 2016). Along that continuum, studies dealing with conceptual transfer (e.g., Pavlenko \& Malt 2011; Otwinowska 2015; Alonso Alonso, Cadierno \& Jarvis 2016) imply their own general research question and make use of data related to verbal responses, thus implying a thinking-for-speaking interpretation of conceptual transfer (von Stutterheim \& Nüse 2003; von Stutterheim \& Lambert 2005; Cadierno 2008; Bylund \& Jarvis 2011; Vanek \& Hendriks 2015; Ekiert \& Han 2016), speech-accompanying gestures (Negueruela et al. 2004; Brown \& Gullberg 2011; Stam 2010), data related to linguistic relativity effects measured in form of nonverbal behaviour (Papafragou, Massey, \& Gleitman 2002; Athanasopoulos 2006; Papafragou \& Selimis 2010; Pavlenko 2011; Athanasopoulos et al. 2015; Lucy 2016; Vanek 2017, 2020; Vanek \& Selinker 2017; for an overview of linguistic relativity in SLA see Bylund \& Athanasopoulos 2014) or a combination of both verbal and non-verbal data (Pavlenko 1999; Park 2020).

It is important to note that each of the theoretical perspectives, thinking-forspeaking, linguistic relativity, and cognitive linguistics, deal with different theoretical and methodological constructs when investigating transfer effects in multilinguals (see Ewert 2016). It has been claimed that, for example, viable evidence for relativistic effects in crosslinguistic influence research is best found in nonverbal data (Odlin 2008, 2010; Bylund \& Athanasopoulos 2014), while thinking-for-speaking effects in second language use are best investigated through the use of verbal data (Jarvis 2007, 2016). The definition of conceptual transfer given above also presumes that, in contrast to Odlin $(2005,2008,2010)$, who has stated that conceptual transfer is "crosslinguistic influence involving relativistic effects" (2008: 306), the scope of conceptual transfer studies extends to the investigation of effects of thinking-for-speaking and crosslinguistic influence at the conceptual level.

The results of studies approaching conceptual transfer through cognitive linguistics can thus inform us about either the transfer of mental representations (linguistic relativity) or the transfer of mental processes that are activated during the formulation of linguistic expression (thinking for speaking). This distinction is important as it pertains to what is effected by CLI: concepts or conceptualizations (Jarvis 2007: 50ff, 2011: 3ff Ewert 2016: 384;). In 2.1, the idea of conceptualization in the CL framework was discussed. In contrast, a concept in CL is a relatively stable cognitive entity representing the perceptual experience with the environment and the prerequisite for semantic structure (Johnson 1987; Evans 2011; Barsalou 2017). Concepts consist of images schemas (Lakoff \& Johnson 1980), derived from embodied experience, and are linked to the meaning associated with a particular linguistic symbol (Evans \& Green 2006: 7), whereby the image that 'pops up' corresponds to a conventional meaning of 
an entity. Concepts are structured in the conceptual system in which embodied experience is organized into schematic categories, such as the attentional system or the force-dynamics system (Talmy 2000). Crucially, while concepts are rather relatively stable representations, they are modified and reshaped by recurrent experiences over time. Studies seeking for concept transfer are closely associated with a linguistic-relativity interpretation of conceptual transfer effects in SLA and often include nonverbal data collection tools (e.g., Malt \& Sloman 2003; Athanasopoulos et al. 2011) while conceptualization transfer studies look into the language-specific patterns of information organization in SLA (e.g., Hohenstein, Eisenberg \& Naigles 2006; Brown \& Gullberg 2011; Flecken 2011; von Stutterheim et al. 2012).

\subsection{Conceptual transfer effects in event construal: Previous studies}

Research on CLI effects in event conceptualization has accumulated substantially over the past ten years (Majid, Boster \& Bowerman 2008; Pavlenko \& Driagina 2008; Brown \& Gullberg 2011; Cheung, Matthews \& Tsang 2011; Daller, Treffers-Daller \& Furman 2011; De Angelis \& Dewaele 2011; Schmiedtová 2011, 2013; McManus 2015; Leclercq \& Edmonds 2017; Saddour 2017; Vanek \& Selinker 2017). These empirical accounts include work on multilinguals' differences in conceptualization patterns of grammatical aspect (Chin 2008; Bylund \& Jarvis 2011; Flecken 2011; Flecken et al. 2015; Vanek \& Hendriks 2015; Andreou \& Tsimpli 2017; Vanek 2020), processes and states (Krajinovic $\&$ Pevec 2015) as well as how multilinguals refer to endpoints in event-time structures (von Stutterheim 2003; Bylund \& Jarvis 2011). Their work has shown that differences in the conceptual representational system may result in speaker's failure to create appropriate links between types of events and the corresponding grammaticised and lexicalised concepts in the target language or to distinguish between two related but distinct tense categories. ${ }^{5}$

Regarding the application of CL and CG in conceptual transfer studies, it appears that previous research has focused primarily on the effect of typological differences of L2 speaker's conceptualization and expression of spatial relations, thus employing Talmy's typological framework in the context of crosslinguistic influence in SLA (overview in Cadierno \& Lund 2004). The potential of the cognitive perspective on grammar, however, and its applicability to crosslinguistic and SLA research has not been fully realized. While some studies (Bylund \& Jarvis 2011; Krajnović \& Pevec 2015; Austen 2016, 2017) deal with the potential of CG-inspired descriptions in investigating the relationship of grammatical tense/aspect and event construal in SLA, other works on event

For a comprehensive overview, see Jarvis \& Pavlenko (2008), Jarvis (2011), Ewert (2016). 
conceptualization (see references above) have not explicitly made use of the CG framework to examine how language-specific conceptual distinction and patterns of information organization affect L2 use. ${ }^{6}$

For example, Bylund and Jarvis (2011) studied whether typological differences regarding grammatical aspect would influence L1 Spanish-L2 Swedish bilinguals' sensitivity to tense and aspect use, particularly to their reference to motion endpoints. They utilized CG principles to test the bilinguals' choice of the progressive and non-progressive, a distinction made in terms of the profile/base alignment and perspective. The results revealed the influence of L2 Swedish on the bilinguals' preference to mention the endpoint: while Spanish-Swedish bilinguals attended to the boundedness of the event, the Spanish monolinguals were more prone to emphasise the course of the action. Different factors that influence the pattern of endpoint coding and use of tense, such as overall proficiency and the age of onset of L2 acquisition, were taken into consideration. Bylund and Jarvis found that particularly those bilinguals who came into contact with Swedish before their Spanish construal event patterns were entrenched preferred to mention the endpoint rather than the ongoingness of an event. They interpret these results as showing L2 conceptual influence on L1. CG holds that the frequent use of any construction (and construal pattern) makes the process of its generalisation and acquisition easier. Certain grammatical constructions are more accessible to speakers because they have become entrenched through repeated activation (Langacker 2017; MacWhinney 2017). These frequently-occurring patterns take a more salient role in the speaker's conceptual and linguistic repertoire, which is precisely what was found in their study.

Another intriguing study on the application of CG in conceptual transfer research comes from Krajnović and Pevec (2015) who showed that functional and formal errors made by Croatian learners of English when using the present progressive and present simple construction were a result of entrenched L1 construal patterns. Specifically, they were likely to use the present progressive form with "ambivalent, non-prototypical constructions" (2015: 105) to encode events that are viewed with a maximal viewing frame and usually expressed with the simple present form. They argued that conceptual transfer effects in learner's oral performance can be attributed to the differences in how processes and states are expressed in Croatian and English. When Croatian learners conceptualised a state or stable situation through time, they used the progressive to describe the situation because they created a link between the progressive construction in English and the imperfect aspect of verbs in Croatian. As Krajinovic and Pevec

6 There are numerous researchers (e.g., von Stutterheim, Flecken, Caroll, Vanek, Athanasopoulos) who study patterns of event conceptualization in light of cognitive-oriented principles, but only rarely do they rely explicitly on Langacker's notion of construal. 
stated, "[w]hile learning English constructions that conceptualize, i.e. that express the present, primary school learners mostly made errors in using English PC with ambivalent, non-prototypical constructions whose telic or atelic meaning is constructed according to the situation" (2015: 105).

\section{Conceptual transfer among Finnish and German learners of English ${ }^{7}$}

In this research project, it is attempted to examine whether learners' errors with respect to the expression of temporality using tense and aspect structures in L2 English originate from the different patterns of construal in event conceptualization in the their L1, Finnish and German, respectively. In other words, the question addressed in this project is: Do learners from two different language backgrounds construe the same conceptual content in different ways? In this respect, the project investigates and compares construal patterns of temporal relationships, as presented in section 3, employed by L2 learners and native speakers to ascertain whether the differing tendencies for expressing temporality can be attributed to conceptual transfer.

In line with Jarvis' $(2016,2017)$ methodological framework of studying conceptual transfer, this work compares the written language produced by English native speakers in the use of the tense and aspect structures with the results produced by Finnish learners and German learners of English; this will be done to see whether the learners' choices and preferences in L2 English reflect the patterns of temporal construal in their L1s. It also discuss more closely the results of two control groups, Finnish L1 and German L1 speakers, and the between-group differences found in construal patterns in the expression of temporality. This research uses corpus data to model the L2 properties of written constructions containing tense and aspect forms in two varieties of learner English. The data comes from the International Corpus of Learner English (ICLE), a corpus of argumentative essays on various topics composed by advanced learners of English from different L1 backgrounds. The two learner corpora included in the present work are comparable as they all consist of essays of around 500 words on the same topics. The analysis involves several stages: First, instances of tense/aspect structures (present tense forms, past tense forms, progressive forms) are extracted from the corpus data using WordSmith Tools. Preliminary selection of the tense/aspect structures to be included in the study is done by identifying deviant or atypical tense/aspect forms that most often occur in the German and Finnish component if ICLE. These forms are then subjected

The current post-doctoral research project entitled A Cognitive Grammar perspective on crosslinguistic differences and influence - How can cognitive theories inform foreign language learning and classroom practices? has been financed by the Kone Foundation (2017-2020). 
to closer analysis, which follows the classification scheme for construal patters relevant for expressing temporality presented in Table 1 . Thus, this examination bears testimony to those structures that reveal underlying conceptual differences between the two learner groups in their use of tense and aspect.

Example (15), identified in the German component of ICLE, illustrates the erroneous use of the present perfect or the non-use of the simple past in the required context. Here, the learner's failure to differentiate between the simple past and present perfect points to difficulty to recognise past-tense and presenttense contexts combined with time adverbials (category: temporal reference point, see Table 1). This may originate from the learner's previous (conceptual) experience. In spoken interactions, German L1 speakers tend to use the present perfect construction to refer to the definite past, known as Präteritumsschwund (Fischer 2016). This shift may lead to a behaviour where German speakers construe events in the definite past from a viewpoint located in the present and not from the past (as indicated by the time adverbial yesterday) (cf. Rogatcheva 2012). It could be hypothesized that German speakers learn to conceptualize events that happened in the definite past and come to an end from a present-tense viewpoint. If this is true, it means that German speakers and English speakers rely on different conceptual preferences when deciding whether to use a simple past or present perfect. This behaviour may carry over to their L2 use, as reflected in the differences in the conceptual meanings they express.

(15) Have you been yesterday on the report on the growth of the rubbishmountains? (ICLE-GE-AUG-0033.1)

A word of caution is in order. While learner corpora are a useful tool in particularly native language identification (Jarvis 2017: 22), the questions of whether they are a valuable domain for investigating conceptual transfer has been raised (this, again, pertains to the distinction of nonverbal and verbal data in conceptual transfer studies). As Jarvis (2017) points out, the usefulness of corpora in this area of CLI research depends greatly on the nature of the corpus, especially with regard to the topical selection of the essays. In the German and Finnish component of ICLE, numerous essays on the same topic can be found, thus ensuring that the context across essays are similar and comparisons of learners' expression of conceptual meanings can be made. However, supplementing verbal data with non-verbal responses to tap into the effects of language on cognitive patterns (and perhaps on concepts) represents another methodological possibility for determining conceptual transfer. 


\section{Conclusion}

The overall aim of this article has been to show how cognitive grammar can constitute a promising linguistic paradigm for the study of SLA and particularly for the investigation of how learners' entrenched L1 construal patterns may carry over to their L2. With respect to the contributions in general, it has been argued that cognitive grammar is a particularly promising theoretical framework for the examination of event conceptualization given its view of language structure as a vast symbolic network in which lexical and grammatical elements convey meaning. Its view that language structure is characterized in terms of general cognitive processes (e.g., perception, categorization, schematization, metaphor, imagery, attention, memory, to name a few) and that the semantic value of any expression resides in the form of embodied cognition, makes it especially suited for inquiries examining how linguistic choices are a result of differing construal patterns in L1 and L2 acquisition.

Furthermore, its understanding of how language and cognition interact allows for the establishment of links between linguistic and cognitive approaches to SLA.

Thus, this article has introduced a framework that represents some of the exciting new developments in CLI research that have enlightened our understanding of the cognitive mechanisms that underlie conceptual transfer patters in multilinguals. The discussion presented here shows that using a cognitive-oriented framework to analyze and explain manifestations of conceptual transfer in learners' L2 use can add a new perspective to the question of why CLI effects occur in learners' expression and interpretation of temporality, and, more generally, the process of language learning and language use in multilinguals. As it was presented, there is evidence that shows how L2 learners draw on conceptualization patterns and concepts entrenched in their L1. Only few empirical accounts, however, explicitly draw on CG-oriented descriptions in order to elucidate conceptual representations manifested in language-specific patterns of information organization. It was argued here that the notions of construal and meaning construction deserve more attention in the study of conceptual transfer effects, for they allow more comprehensive explanations of cognitive processes relevant for the conceptualization of TIME, both in L1 and L2 acquisition. The cognitive patterns relevant for the construal of temporal relationships were discussed and illustrated by numerous examples, all of which highlighted the importance of the speaker's active role in communication. The empirical part of the study that will be conducted relies on comparisons of the encoding of time found in the English performance by two different learner groups, Finnish and German. It is hoped that the results of the study will bear testimony to the advantageous effect of employing CG-inspired tools and explanation for comparison of learner's L2. 


\section{REFERENCES}

Achard, Michel. 2004. Grammatical instruction in the natural approach: A cognitive grammar view. In Michel Achard \& Susanne Niemeier, Cognitive linguistics, second language acquisition, and foreign language teaching. Mouton de Gruyter. 165-194. DOI: 10.1515/9783110199857.165

Alonso Alonso, Rosa, Teresa Cadierno \& Scott Jarvis. 2016. Crosslinguistic influence in the acquisition of spatial prepositions in English as a foreign language. In Rosa Alonso Alonso (ed.), Crosslinguistic influence in second language acquisition. Multilingual Matters. 93-120. DOI: 10.21832/9781783094837-008

Andreou, Maria \& Ianthi Tsimpli. 2017. Aspectual distinctions in the narratives of bilingual children. International Review of Applied Linguistics in Language Teaching 55(3). 305-324. DOI: 10.1515/iral-2017-0111

Athanasopoulos, Panos. 2006. Effects of the grammatical representation of number on cognition in bilinguals. Bilingualism: Language and Cognition 9(1). 89-96. DOI: 10.1017/S1366728905002397

Athanasopoulos, Panos, Emanuel Bylund, Guillermo Montero-Melis, Ljubica Damjanovic, Alina Schartner, Alexandra Kibbe, Nick Riches \& Guillaume Thierry. 2015. Two languages, two minds: Flexible cognitive processing driven by language of operation. Psychologcal Science 26(4). 518-526. DOI: 10.1177/0956797614567509

Athanasopoulos, Panos, Ljubica Damjanovic, Andrea Krajciova \& Miho Sasaki. 2011. Representation of colour concepts in bilingual cognition: The case of Japanese blues. Bilingualism: Language and Cognition 14(1). 9-17. DOI: 10.1017/S1366728909990046

Austen, Samantha. 2016. Learner error in second language acquisition: The transfer of form or concept? Unpublished $\mathrm{PhD}$ thesis, Cardiff University.

Austen, Samantha. 2017. Native language (L1) transfer in second language learning: From form to concept, the implications. Xjenza Online - Journal of the Malta Chamber of Scientists 5(1). 77-80. DOI: 10.7423/XJENZA.2017.1.10

Barsalou, Lawrence W. 2017. Cognitively plausible theories of concept composition. In James A. Hampton \& Yoad Winter (eds.), Compositionality and concepts in linguistics and psychology Springer. 9-30. DOI: 10.1007/978-3-319-45977-6_2

Bergen, Benjamin K. 2012. Louder than words: The new science of how the mind makes meaning. Basic Books.

Bergen, Benjamin K. \& Nancy Chang. 2013. Embodied Construction Grammar. In Thomas Hoffmann \& Graeme Trousdale (eds.), The Oxford handbook of Construction Grammar. Oxford University Press. 168-190 DOI: 10.1093/oxfordhb/9780195396683.013.0010

Boogaart Ronny \& Theo Janssen. 2007. Tense and aspect. In Dirk Geeraerts (ed.), The Oxford handbook of cognitive linguistics. Oxford University Press. 803-828.

Brisard, Frank. 2013. An account of English tense and aspect in Cognitive Grammar. In Kasia M. Jaszczolt \& Louis de Saussure (eds.), Time: Language, cognition, and reality. Oxford: Oxford University $210-235 . \quad$ Press. 10.1093/acprof:oso/9780199589876.003.0011 
Brown, Amanda \& Marianne Gullberg. 2011. Bidirectional cross-linguistic influence in event conceptualization? Expressions of Path among Japanese learners of English. Bilingualism: Language and Cognition 14(1). 79-94. DOI: 10.1017/S1366728910000064

Bybee, Joan 2010. Language, usage and cognition. Cambridge University Press. DOI: 10.1017/CBO9780511750526

Bylund, Emanuel \& Scott Jarvis. 2011. L2 effects on L1 event conceptualization. Bilingualism: Language and Cognition 14(1). 47-59. DOI: 10.1017/S1366728910000180

Bylund, Emanuel \& Panos Athanasopoulos. 2014. Linguistic relativity in SLA: Toward a new research program. Language Learning 64(4). 952-985. DOI: 10.1111/lang.12080

Cadierno, Teresa. 2008. Learning to talk about motion in a foreign language. In Peter Robinson \& Nick C. Ellis (eds.), Handbook of cognitive linguistics and second language acquisition. Routledge. 239-275.

Cadierno, Teresa \& Karen Lund. 2004. Cognitive linguistics and second language acquisition: Motion events in a typological framework. In Bill VanPatten, Jessica Williams, Susanne Rott \& Mark Overstreet (eds.), Form-meaning connections in second language acquisition. Erlbaum. 139-154.

Casad, Eugene H. 1996. Seeing it in more than one way. In John R. Taylor \& Robert E. MacLaury (eds.) Language and the cognitive construal of the world. Mouton de Gruyter. 23-50. DOI: $10.1515 / 9783110809305.23$

Cheung, Anna S. C., Stephen Matthews \& Wai Lan Tsang. 2011. Transfer from L3 German to L2 English in the domain of tense/aspect. In Gessica De Angelis \& Jean-Marc Dewaele (eds.), New trends in crosslinguistic influence and multilingualism research. Multilingual Matters. 53-73. DOI: 10.21832/9781847694430-005

Chin, Diana Hsien-jen. 2008. A cross-linguistic investigation on the acquisition of Spanish aspect. In Joyce Bruhn de Garavito \& Elena Valenzuela (eds.), Selected proceedings of the 10th Hispanic Linguistics Symposium. Cascadilla Proceedings Project. 36-50.

Croft, William \& D. Alan Cruse. 2004. Cognitive linguistics. Cambridge University Press.

Daller, Michael H., Jeanine Treffers-Daller \& Reyhan Furman. 2011. Transfer of conceptualisation patterns in bilinguals: The construal of motion events in Turkish and German. Bilingualism: Language and Cognition 14(1), 95-119. DOI: 10.1017/S1366728910000106

De Angelis, Gessica \& Jean-Marc Dewaele (eds.). 2011. New trends in crosslinguistic influence and multilingualism research. Multilingual Matters.

De Wit Astrid \& Frank Brisard. 2014. A cognitive grammar account of the semantics of the English present progressive. Journal of Linguistics 50(1) 49-90. DOI: 10.1017/S0022226713000169

Droźdź, Grzegorz. 2018. The Cognitive Grammar-based pedagogical grammar - tenses. Paper presented at the PCLA Conference, Poznań, Poland.

Ellis, Nick C. \& Teresa Cadierno. 2009. Constructing a second language: Introduction to the special section. Annual Review of Cognitive Linguistics 7. 111-139. DOI: 10.1075/arcl.7.05ell

Ekiert, Monika \& ZhaoHong Han. 2016. L1-fraught difficulty: The case of L2 acquisition of English articles by Slavic speakers. In Rosa Alonso Alonso (ed.), Crosslinguistic influence in second language acquisition. Multilingual Matters. 147-172. DOI: $10.21832 / 9781783094837-010$ 
Evans, Vyvyan. 2011. Language and cognition: The view from cognitive linguistics. In Vivian Cook \& Benedetta Bassetti (eds.), Language and bilingual cognition. Psychology Press. 69-107.

Evans, Vyvyan. 2019. Cognitive linguistics: A complete guide. Edinburgh University Press.

Evans, Vyvyan \& Melanie Green. 2006. Cognitive linguistics: An introduction. Routledge.

Ewert, Anna. 2016. Space, motion and thinking for language. In Vivian Cook \& Li Wei (eds), The Cambridge handbook of linguistic multi-competence. Cambridge University Press. 376-402. DOI: 10.1017/CBO9781107425965.018

Fischer, Hanna. 2016. Präteritumschwund im Deutschen. Dokumentation und Erklärung eines Veränderungsprozesses. De Gruyter Mouton.

Flecken, Monique. 2011. Event conceptualization by early Dutch-German bilinguals: Insights from linguistic and eye-tracking data. Bilingualism: Language and Cognition 14(1). 61-77. DOI: $10.1017 / S 1366728910000027$

Flecken, Monique, Mary Carroll, Katja Weimar \& Christiane von Stutterheim. 2015. Driving along the road or heading for the village? Conceptual differences underlying motion event encoding in French, German, and French-German L2 users. Modern Language Journal 99(S1). 100-122. DOI: 10.1111/j.1540-4781.2015.12181.x

Givón, Talmy. 1989. Mind, code, and context: Essays in pragmatics. Erlbaum.

Han, ZhaoHong \& Teresa Cadierno (eds). 2010. Linguistic relativity in SLA: Thinking for speaking. Multilingual Matters.

Hohenstein, Jill, Letitia R. Naigles \& Ann R. Eisenberg. 2006. Keeping verb acquisition in motion: A comparison of English and Spanish. In D. Geoffrey Hall \& Sandra R. Waxman (eds.), Weaving a lexicon. MIT Press. 569-602.

Jarvis, Scott. 2007. Theoretical and methodological issues in the investigation of conceptual transfer. VIAL 4. 43-71.

Jarvis, Scott. 2011. Conceptual transfer: Crosslinguistic effects in categorization and construal. Bilingualism: Language and Cognition 14(1). 1-8. DOI: $10.1017 / \mathrm{S} 1366728910000155$

Jarvis, Scott. 2016. Clarifying the scope of conceptual transfer. Language Learning 66(3). 608635. DOI: $10.1111 /$ lang. 12154

Jarvis Scott. 2017. Transfer: An overview with an expanded scope. In Anne Golden, Scott Jarvis \& Kari Tenfjord, Crosslinguistic influence and distinctive patterns of language learning: Findings and insights from a learner corpus. Multilingual Matters. 12-28. DOI: 10.21832/9781783098774-004

Jarvis, Scott \& Terence Odlin. 2000. Morphological type, spatial reference, and language transfer. Studies in Second Language Acquisition 22(4). 535-556. DOI: 10.1017/S0272263100004034

Jarvis, Scott \& Aneta Pavlenko. 2008. Crosslinguistic influence in language and cognition. Routledge.

Johnson, Mark. 1987. The body in the mind: The bodily basis of meaning, imagination, and reasoning. University of Chicago Press.

Krajnović, Marta Medved \& Irena Kocijan Pevec. 2015. Present Tense Devlopment in 11- to 13Year-Old EFL Learners. In Jelena Mihaljević Djigunović \& Marta Medved Krajnović (eds), Early learning and teaching of English: New dynamics of primary English. Multilingual Matters. 80-109. 
Kroll, Judith F. \& Mary C. Potter. 1984. Recognizing words, pictures, and concepts: A comparison of lexical, object, and reality decisions. Journal of Verbal Learning and Verbal Behavior 23(1). 39-66. DOI: 10.1016/S0022-5371(84)90499-7

Lakoff, George. 1987. Women, fire, and dangerous things: What categories reveal about the mind. University of Chicago Press.

Lakoff, George. 1990. The invariance hypothesis: Is abstract reason based on image schemas? Cognitive Linguistics 1(1). 39-74. DOI: 10.1515/cogl.1990.1.1.39

Lakoff, George \& Mark Johnson. 1980. Metaphors we live by. University of Chicago Press.

Langacker, Ronald W. 1987. Foundations of cognitive grammar. Stanford University Press.

Langacker, Ronald W. 1990. Subjectification. Cognitive Linguistics 1(1). 5-38. DOI: 10.1515/cogl.1990.1.1.5

Langacker, Ronald W. 1991. Foundations of cognitive grammar: Vol. 2: Descriptive applications. Stanford University Press.

Langacker, Ronald W. 1996. Viewing in cognition and grammar. In Philip W. Davis (ed.), Alternative linguistics: Descriptive and theoretical modes. John Benjamins. 153-212. DOI: $10.1075 /$ cilt.102.06lan

Langacker, Ronald W. 1999. Grammar and conceptualization. Berlin/New York: Mouton de Gruyter. DOI: 10.1515/9783110800524

Langacker, Ronald W. 2000. A dynamic usage-based model. In Michael Barlow \& Suzanne Kemmer (eds.), Usage-based models of language. University of Chicago Press. 1-63.

Langacker, Ronald W. 2007. Cognitive Grammar. In Dirk Geeraerts \& Hubert Cuyckens (eds.), The Oxford handbook of cognitive linguistics. Oxford University Press. 421-462.

Langacker, Ronald W. 2008. Cognitive grammar: A basic introduction. Oxford University Press.

Langacker, Ronald W. 2017. Entrenchment in cognitive grammar. In Hans-Jörg Schmid (ed.), Entrenchment and the psychology of language learning: How we reorganize and adapt linguistic knowledge. De Gruyter Mouton. 39-56. DOI: 10.1515/9783110341423-003

Leclercq, Pascale \& Amanda Edmonds. 2017. How L2 learners of French and English express modality using verbal means: A crosslinguistic and developmental study. International Review of Applied Linguistics in Language Teaching 55(3). 265-282. DOI: 10.1515/iral-2017-0108

Lucy, John A. 2016. Recent advances in the study of linguistic relativity in historical context: A critical assessment. Language Learning 66(3). 487-515. DOI: 10.1111/lang.12195

Majid, Asifa, James S. Boster \& Melissa Bowerman. 2008. The cross-linguistic categorization of everyday events: A study of cutting and breaking. Cognition 109(2). 235-250. DOI: 10.1016/j.cognition.2008.08.009

MacWhinney, Brian. 1992. Transfer and competition in second language learning. In Richard Jackson Harris (ed.), Cognitive processing in bilinguals. North Holland. 371-390. DOI: 10.1016/S0166-4115(08)61506-X

MacWhinney, Brian. 2017. Entrenchment in second-language learning. In Hans-Jörg Schmid (ed.), Entrenchment and the psychology of language learning: How we reorganize and adapt linguistic knowledge. De Gruyter Mouton. 343-366. DOI: 10.1515/9783110341423-016

Malt, Barbara C. \& Steven A. Sloman. 2003. Linguistic diversity and object naming by non-native speakers of English. Bilingualism: Language and Cognition 6(1). 47-67. DOI: 10.1017/S1366728903001020

McManus, Kevin. 2015. L1-L2 differences in the acquisition of form-meaning pairings: A comparison of English and German learners of French. Canadian Modern Language Review 71(2). 155-181. DOI: 10.3138/cmlr.2070.51 
Michaelis, Laura A. 2004. Type shifting in construction grammar: An integrated approach to aspectual coercion. Cognitive Linguistics 15(1). 1-67. DOI: 10.1515/cogl.2004.001

Negueruela, Eduardo, James P. Lantolf, Stefanie Rehn Jordan \& Jaime Gelabert. 2004. The "private function" of gesture in second language speaking activity: A study of motion verbs and gesturing in English and Spanish. International Journal of Applied Linguistics 14(1). 113-147. DOI: 10.1111/j.1473-4192.2004.00056.x

Niemeier, Susanne. 2013. A Cognitive Grammar perspective on tense and aspect. In M. Rafael Salaberry \& Llorenç Comajoan (eds.), Research design and methodology in studies on L2 tense and aspect. Mouton de Gruyter. 11-56. DOI: 10.1515/9781934078167.11

Odlin, Terence. 2005. Crosslinguistic influence and conceptual transfer: What are the concepts? Annual Review of Applied Linguistics 25. 3-25. DOI: 10.1017/S0267190505000012

Odlin, Terence. 2008. Conceptual transfer and meaning extensions. In Peter Robinson \& Nick C. Ellis (eds), Handbook of cognitive linguistics and second language acquisition. Routledge. 360-340.

Odlin, Terence. 2010. Conclusion: On the interdependence of conceptual transfer and relativity studies. In ZhaoHong Han \& Teresa Cadierno (eds.), Linguistic relativity in SLA. Thinking for speaking. Multilingual Matters. 183-194. DOI: $10.21832 / 9781847692788-010$

Otwinowska, Agnieszka. 2015. Cognate vocabulary in language acquisition and use: Attitudes, awareness, activation. Multilingual Matters.

Papafragou, Anna, Christine Massey \& Lila Gleitman. 2002. Shake, rattle, 'n' roll: The representation of motion in language and cognition. Cognition 84. 189-219.

Papafragou, Anna \& Stathis Selimis. 2010. Event categorisation and language: A cross-linguistic study of motion. Language and Cognitive Processes 25(2). 224-260. DOI: 10.1080/01690960903017000

Park, Hae In. 2020. How do Korean-English bilinguals speak and think about motion events? Evidence from verbal and non-verbal tasks. Bilingualism: Language and Cognition 23(3). 483-499. DOI: 10.1017/S1366728918001074

Park, Hae In \& Nicole Ziegler. 2014. Cognitive shift in the bilingual mind: Spatial concepts in Korean-English bilinguals. Bilingualism: Language and Cognition 17(2). 410-430. DOI: $10.1017 / \mathrm{S} 1366728913000400$

Pavlenko, Aneta. 1999. New approaches to concepts in bilingual memory. Bilingualism: Language and Cognition 2(3). 209-230. DOI: 10.1017/S1366728999000322

Pavlenko, Aneta. 2000. Access to linguistic resources: Key variable in second language learning. Estudios de Sociolingüistica. 1(2). 85-105. DOI: 10.1558/sols.v1i2.85

Pavlenko, Aneta (ed.). 2011. Thinking and speaking in two languages. Multilingual Matters.

Pavlenko, Aneta \& Viktoria Driagina. 2008. Narrative and conceptual proficiency in Russian. Center for Advanced Language Proficiency Education and Research, The Pennsylvania State University.

Pavlenko, Aneta \& Barbara C. Malt. 2011. Kitchen Russian: Cross-linguistic differences and firstlanguage object naming by Russian-English bilinguals. Bilingualism: Language and Cognition. 14(1). 19-45. DOI: 10.1017/S136672891000026X

Radden, Günter \& René Dirven. 2007. Cognitive English grammar. John Benjamins. DOI: 10.1075/clip. 2 
Rogatcheva, Svetla. 2012. Perfect problems: A corpus-based comparison of the perfect in Bulgarian and German EFL writing. In Sebastian Hoffmann, Paul Rayson \& Geoffrey Leech (eds.), English corpus linguistics: Looking back, moving forward. Brill. 149-163. DOI: 10.1163/9789401207478_011

Saddour, Inès. 2012. Expressing simultaneity using aspect. A comparison of oral productions in French L1, Tunisian Arabic L1, and French L2 by Tunisian learners. In Luna Filipović \& Katarzyna M. Jaszczolt (eds), Space and time in languages and cultures: Linguistic diversity. John Benjamins. 325-346. DOI: 10.1075/hcp.36.17sad

Saddour, Inès. 2017. A multimodal approach to investigating temporality expression in L2: What does gesture analysis reveal? International Review of Applied Linguistics in Language Teaching 55(3). 283-304. DOI: 10.1515/iral-2017-0112

Schmiedtová, Barbara. 2011. Do L2 speakers think in the L1 when speaking in the L2? VIAL 8. 97 122.

Schmiedtová, Barbara. 2013. Traces of L1 patterns in the event construal of Czech advanced speakers of L2 English and L2 German. International Review of Applied Linguistics in Language Teaching 51(2). 87-116. DOI: 10.1515/iral-2013-0005

Stam, Gale. 2010. Can a L2 speaker's patterns of thinking for speaking change? In ZhaoHong Han \& Teresa Cadierno (eds.), Linguistic relativity in SLA: Thinking for speaking. Multilingual Matters. 59-83.

Talmy, Leonard. 1985. Lexicalization patterns: Semantic structure in lexical forms. In Timothy Shopen (ed.), Language typology and syntactic description. Vol. 3: Grammatical categories and the lexicon. Cambridge University Press. 225-282.

Talmy, Leonard. 1991. Path to realization: A typology of event conflation. In Laurel A. Sutton \& Christopher Johnson (eds.), Proceedings of the 17th annual meeting of the Berkeley Linguistics Society: General session and parasession on the grammar of event structure. Berkeley Linguistic Society. 480-519. DOI: 10.3765/bls.v17i0.1620

Talmy, Leonard. 1996. The windowing of attention in language. In Masayoshi Shibatani \& Sandra A. Thompson (eds.), Grammatical construction: Their form and meaning. Oxford University Press. 235-287.

Talmy, Leonard. 2000. Toward a cognitive semantics. Vol. 1: Concept structuring systems. MIT Press.

Tomasello, Michael. 2003. Constructing a language: A usage-based theory of language acquisition. Harvard University Press.

Vanek, Norbert. 2017. 'It starts to explode'. Phasal segmentation of contextualised events in L2 English. In Martin Howard \& Pascale Leclercq (eds.), Tense-aspect-modality in a second language: Contemporary perspectives. John Benjamins. 145-182. DOI: 10.1075/sibil.50.06van

Vanek, Norbert. 2020. Changing event categorization in second language users through perceptual learning. Language Learning 70(2). 309-348. DOI: 10.1111/lang.12377

Vanek, Norbert \& Henriëtte Hendriks. 2015. Convergence of temporal reference frames in sequential bilinguals: Event structuring unique to second language users. Bilingualism: Language and Cognition 18(4). 753-768. DOI: 10.1017/S1366728914000765

Vanek, Norbert \& Larry Selinker. 2017. Covariation between temporal interlanguage features and nonverbal event categorisation. International Review of Applied Linguistics in Language Teaching 55(3). 223-234. DOI: 10.1515/iral-2017-0106

Verhagen, Arie. 2007. Construal and perspectivization. In Dirk Geeraerts (ed.), The Oxford handbook of cognitive linguistics. Oxford University Press. 48-81. 


\section{F. Kermer}

von Stutterheim, Christiane. 2003. Linguistic structures and information organisation: The case of very advanced learners. EUROSLA Yearbook 3. 183-206. DOI: 10.1075/eurosla.3.11stu

von Stutterheim, Christiane, Martin Andermann, Mary Carroll, Monique Flecken \& Barbara Schmiedtová. 2012. How grammaticized concepts shape event conceptualization in language production: Insights from linguistic analysis, eye tracking data, and memory performance. Linguistics 50(4). 833-867. DOI: 10.1515/ling-2012-0026

von Stutterheim, Christiane \& Monique Lambert. 2005. Cross-linguistic analysis of temporal perspectives in text production. In Henriëtte Hendriks (ed.), The structure of learner varieties. Mouton de Gruyter. 203-230. DOI: 10.1515/9783110909593.203

von Stutterheim, Christiane \& Ralf Nüse. 2003. Processes of conceptualization in language production: Language-specific perspectives and event construal. Linguistics 41(5). 851-881. DOI: 10.1515/ling.2003.028

Zagona, Karen. 2007. Some effects of aspect on tense construal. Lingua 117(2). 464-502. DOI: 10.1016/j.lingua.2005.08.004 